\title{
Linfoma nasal de células T/NK (granuloma letal de la línea media), una neoplasia agresiva. Reporte de un caso
}

\author{
Nasal T/NK-cell lymphoma (lethal midline granuloma), an aggressive neoplasia. \\ Report of a case
}

\author{
José I. Castro B ${ }^{1}$, Mario J. Jiménez $\mathrm{H}^{2}$, Sandra Herrera L³.
}

\begin{abstract}
RESUMEN
El linfoma nasal de células T/NK es una neoplasia agresiva, infrecuente, con predilección por el sexo masculino. Representa el 1,5\% del total de linfomas no Hodgkin, el grupo etáreo más afectado es entre 40 a 80 años. Su etiología es desconocida, pero se ha asociado con el virus de Epstein Barr. Se presenta el caso de una paciente mujer de 40 años, con dolor e induración de fosa nasal derecha asociado a secreción fétida, seropurulenta de 3 meses de evolución. Estudio histopatológico, reporta linfoma nasal de células T/NK. La paciente recibe quimioterapia, con mejoría clínica sustancial. El linfoma T/NK es una neoplasia con sintomatología inespecífica, predominio que afecta nasofaringe, amígdalas y base de la lengua. Entre las manifestaciones encontramos dolor de garganta, obstrucción nasal, rinorrea, epistaxis y cefalea. El diagnóstico se sospecha con imágenes, pero es necesaria la confirmación histológica con marcadores de inmunohistoquímica CD45Ro, CD43, CD3, CD2, CD45Ro entre otros. Muchos casos suelen detectarse en fase tardía, cuando ya son evidentes los signos radiológicos de destrucción ósea. El diagnóstico diferencial incluye lesiones infecciosas o inflamatorias, la bola fúngica fue el diagnóstico inicial realizado en esta paciente. El tratamiento suele realizarse con radioterapia y quimioterapia.
\end{abstract}

Palabras clave: Bola fúngica, linfoma NK, virus de Epstein Barr.

\begin{abstract}
Nasal T-cell / NK lymphoma is an uncommon aggressive neoplasm with male predilection. It represents $1.5 \%$ of the total number of non-Hodgkin's lymphomas, the most affected age group is 40-80 years. Its etiology is unknown but has been associated with the Epstein Barr virus. We present the case of a female patient of 40 years, with pain and

\footnotetext{
1 Médico Interno. Grupo de Investigación Centro de Investigaciones Biomédicas, CIB. Facultad de Medicina, Universidad de Cartagena. Cartagena, Colombia.

2 Médico Interno. Facultad de Medicina, Universidad de Cartagena. Cartagena, Colombia.

3 Médica Patóloga. Docente del Departamento de Patología. Grupo de Investigación Centro de Investigaciones Biomédicas, CIB. Facultad de Medicina, Universidad de Cartagena. Cartagena, Colombia.
}

Recibido el 14 de junio, 2017. Aceptado el 3 de octubre, 2017. 
induration of the right nostril associated with fetid secretion, seropurulent of 3 months of evolution. Histopathological study, reports T-cell / NK nasal lymphoma. The patient receives chemotherapy, with substantial clinical improvement. T / NK lymphoma is a neoplasm with predominant non-specific symptomatology, affecting the nasopharynx, tonsils and base of the tongue. Among the manifestations we find sore throat, nasal obstruction, rhinorrhea, epistaxis and headache. Diagnosis is suspected with imaging, but histological confirmation with immunohistochemical markers CD45Ro, CD43, CD3, CD2, CD45Ro, among others is required. Many cases are usually detected in the late phase, when radiological signs of bone destruction are already visible. The differential diagnosis includes infectious or inflammatory lesions, the fungal ball was the initial diagnosis made in this patient. Treatment is usually done with radiotherapy and chemotherapy.

Key words: Fungal ball, NK Iymphoma, Epstein Barr virus.

\section{INTRODUCCIÓN}

Los linfomas constituyen un grupo heterogéneo de enfermedades malignas, caracterizadas por la proliferación neoplásica del sistema linforreticular. Se dividen en dos grupos: linfomas Hodgkin (LH) y linfomas no Hodgkin (LNH). En estos últimos se estima que menos del $15 \%$ se presentan como extragangliones ${ }^{1}$.

Dentro de los LNH están los linfomas T/NK tipo nasal2. La denominación "nasal" hace referencia a su presentación mediofacial, que es la más común, constituyendo una masa en fosa nasal, con clínica de obstrucción. Aparte de la afectación de la vía aerodigestiva superior como fosas nasales, nasofaringe, orofaringe, cavidad oral, paladar, senos paranasales, se ha descrito en otras localizaciones como piel, intestino y testículos ${ }^{3-5}$. Su incidencia es baja en Occidente, representando el 1,5\% de todos los linfomas no Hodgkin 6 .

Su etiología es desconocida, pero la presencia del virus Epstein-Barr es una constante, lo que sugiere un papel etiopatogénico importante ${ }^{7}$. Deriva en su mayoría de células NK (CD2+/CD56+), y en menor proporción de células T periféricas (CD2+/ CD56-) de fenotipo T citotóxico (postímicas).

Suele caracterizarse por un curso clínico rápidamente progresivo, con afectación de varias regiones extraganglionares ${ }^{8}$. Es más frecuente en el sexo masculino, y suele darse en adultos jóvenes. Es un linfoma de alto grado, con pronóstico infausto ${ }^{9}$.

\section{CASO CLÍNICO}

Mujer de 40 años de edad, originaria de Sincelejo (Sucre), Colombia; consulta al servicio de otorrinolaringología por presentar cuadro de 3 meses de evolución, consistente en dolor e induración en fosa nasal derecha, asociado a secreción seropurulenta fétida. Fue tratada inicialmente como sinusitis micótica necrotizante sin mejoría. Al examen físico se observa lesión exofítica, cauchosa, irregular, con áreas de necrosis, sangrante que infiltra la pared lateral, piso y ala nasal derecha.

Estudios imagenológicos de resonancia nuclear magnética y tomografía computarizada, reportan una lesión sólida con densidad de tejidos blandos, bordes mal definidos, que ocupa la fosa nasal, involucrando todas las estructuras endonasales, con destrucción y abombamiento de la pared medial del seno maxilar derecho, obliteración de ostium, del seno frontal y celdas etmoidales (Figura 1).

La nasofibrolaringoscopía evidencia gran lesión que compromete todas las estructuras endonasales, infiltra piel del vestíbulo nasal y se extiende hasta el borde de la narina, la lesión sangra fácilmente al tacto, lo cual impide el paso por las coanas. Se realiza biopsia cuyo estudio anatomopatológico reporta células neoplásicas monomórficas, con figuras mitóticas y focos de necrosis coagulativa, dispuestas difusamente, destruye hueso; el epitelio escamoso de revestimiento no presenta cambios displásicos. La neoplasia ex- 


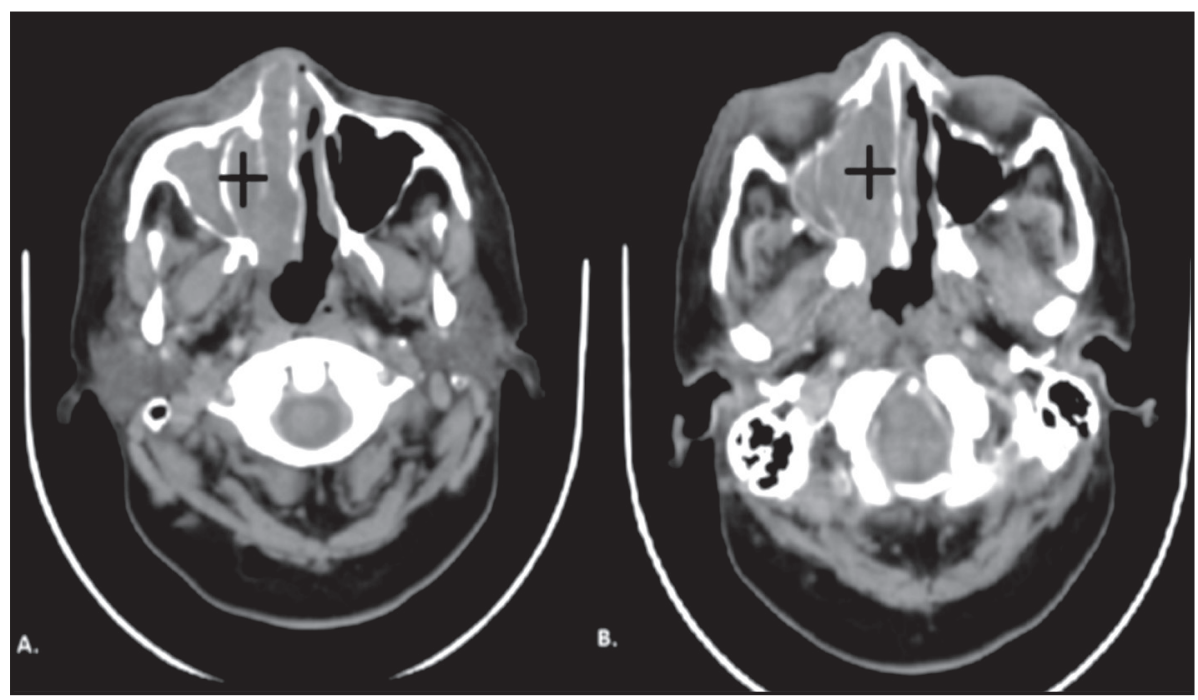

Figura 1. Tomografía computarizada de cavidades paranasales. (A) Lesión sólida de aspecto maligno, bordes mal definidos, con destrucción y abombamiento de la pared medial del seno maxilar derecho, obliteración del ostium frontal y celdas etmoidales. (B) Lesión que compromete la línea media, así como también tejido óseo y blando en fosa nasal derecha.

presa CD3 con coexpresión de CD56, con pérdida de expresión de CD2, CD4, CD8, CD7 y CD5, tampoco hay reactividad para CD30. Hay expresión de marcadores citotóxicos (granzima y perforina). El índice de proliferación celular medido con Ki67 es alto (Figura 2). Se concluye el diagnóstico de linfoma no Hodgkin de células NK/T extranodal de tipo nasal. La paciente es sometida a quimioterapia, presentando disminución de la masa y evolución satisfactoria tras 12 meses de seguimiento.

\section{DISCUSIÓN}

La importancia de la descripción de este caso radica en la rareza de la patología, así como el

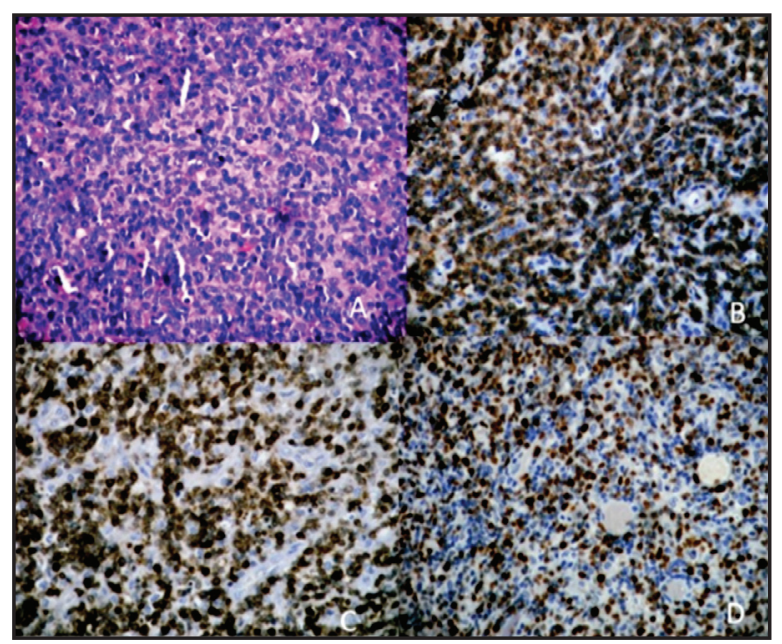

Figura 2. Análisis histológico de la lesión. (A) Vista microscópica en hematoxilina y eosina, muestra una proliferación linfoide de alto grado. (B) positividad para CD56. (C) Positividad para CD3. (D) Muestra un índice de proliferación en 70\%, medido con Ki67. 
desenlace de la misma. El linfoma nasal de células T/NK, es una neoplasia infrecuente, corresponde el $1,5 \%$ de los LNH (menos de 1 caso por 100.000 habitantes/año) ${ }^{4}$. Hay una mayor incidencia en los adultos mayores entre 40 y 80 años, especialmente hombres. La proporción de presentación es de $3: 1$ para las mujeres ${ }^{10,11}$. Aunque nuestra paciente pertenece al rango etario antes mencionado, es de sexo femenino, contrariando las estadísticas que se presentan a nivel mundial con prevalencia en el sexo masculino.

El linfoma nasal de células T/NK fue descrito en 1897 por Mc Bride en el cual hacía referencia al primer caso de "Linfoma Centrofacial". Ha recibido varios nombres a lo largo de la historia "Síndrome de Stewart", "Granuloma letal de la línea media", entre otros. Hacia 1970 comienzan las marcaciones inmunohistoquímicas y genéticas, las cuales permitieron identificarlo como linfoma no Hodgkin extranodal. Actualmente se denomina linfoma de células T/NK extranodal, por la Organización Mundial de la Salud ${ }^{12}$.

Esta patología tiene una menor relación con el ámbito tabáquico. Se ha encontrado que tiene la particularidad de diseminarse a ganglios linfáticos regionales y a distancia ${ }^{4}$. La sintomatología es inespecífica, y consiste en dolor de garganta, dolor en rinofaringe, obstrucción nasal, rinorrea purulenta, epistaxis y dolor de cabeza. Por las extensas áreas de necrosis presentes en esta neoplasia, puede requerirse más de una biopsia para realizar el diagnóstico. En términos generales se hace necesaria más de una intervención para evaluación anatomopatológica del tejido tumoral, situación que retrasa el diagnóstico y tratamiento, lo cual impacta negativamente en el pronóstico del paciente ${ }^{10}$.

Por otra parte se ha encontrado relación entre el virus de Epstein Barr (VEB) y el desarrollo de enfermedades linfoproliferativas como el linfoma nasal de células T/NK, linfoma Burkitt y el linfoma Hodgkin, entre otros síndromes linfoproliferativos. El VEB puede infectar linfocitos T citotóxicos y células NK durante el contacto célula/célula, con células blanco infectadas por medio del intercambio de material genético viral y subsiguiente transformación de la célula efectora. Se encontró que el VEB se halla presente en las células citotóxicas neoplásicas, demostrando que es capaz de persis- tir en ellas. Se podría especular que los linfocitos T citotóxicos o las células NK se infectarían durante la muerte de la célula blanco afectada, dado que el virus infecta en forma más productiva a las células $B$ y células epiteliales en orofaringe y nasofaringe. La ubicación preferencial de las células citotóxicas infectadas puede explicar la presentación de Ios LNH T asociados al VEB en nasofaringe, vías aéreas y tubo digestivo. EI VEB está consistentemente asociado con estos linfomas sin importar la localización geográfica ${ }^{13}$.

El diagnóstico diferencial se debe realizar con procesos infecciosos como las infecciones micóticas, en esta paciente se realizó un diagnóstico inicial de bola fúngica, y se instauró el respectivo tratamiento antifúngico sin respuesta. Hasta el momento se entiende que la bola fúngica es una entidad poco diagnosticada aunque no infrecuente como se cree, pertenece al grupo de la rinosinusitis fúngica no invasivas, su clínica es similar a la presentada por la paciente, con afectación de senos paranasales y rinorrea; ocurre en adultos y tiene predilección por el sexo femenino $0^{12}$.

El diagnóstico definitivo de los linfomas nasales es histopatológico. Es característico que las biopsias iniciales no sean diagnósticas de malignidad, lo que podría deberse al escaso tamaño de las muestras obtenidas en las biopsias, 0 a la extensa necrosis que suele acompañar a estas lesiones. La necrosis probablemente se debe a la propia angioinvasión 0 a la expresión de un factor de necrosis tumoral (TNF) inducido por el VEB. Estos tumores muestran positividad para los marcadores de inmunohistoquímica CD56, CD2, CD45Ro, CD43 Y CD3 citoplasmático, y negatividad en los marcadores CD57, CD16, CD45Ra, Receptor de linfocitos (TCR), CD3 de superficie ${ }^{12}$. Desafortunadamente muchos casos suelen diagnosticarse en fases avanzadas de la enfermedad, cuando ya están presentes signos destructivos clínicos y radiológicos ${ }^{12}$. Por otro lado el diagnóstico diferencial de una masa nasal es muy amplio y puede generar confusiones en las etapas iniciales.

Los LNT/NK son tumores radiosensibles en los que es posible lograr un control local de la enfermedad, aunque la recidiva es la norma en la mayoría de las series publicadas. Existe un consenso unánime sobre la utilización conjunta de radio (RTP) y quimioterapia (QTP) en estadios 
avanzados. El protocolo de QTP más utilizado es el CHOP, con combinaciones de segunda generación 0 de tercera generación. La dosis de RTP que proporciona un mejor control local es superior a 45-50 Gy, independientemente del volumen tumoral. Otra posibilidad terapéutica es la utilización de un trasplante de médula ósea asociado a QTP ablativa, lo

\section{BIBLIOGRAFÍA}

1. Moreno M, Pierzchalski J, Ivanov M, Verea M, TORCHIARI F. Linfoma extraganglionar de células T/NK: Presentación de un caso clínico y revisión de la literatura. ARCH. Argent Dermato/2014;64: 57-60.

2. Escamilla Y, Díaz J, Bonfill T, Orellana R. Linfoma T/NK extranodal de presentación atípica y difícil diagnóstico. ORL Aragon 2011; 14: 14-6.

3. De la Rosa et al. Linfoma T/NK laringotraqueal: caso clínico. Acta Otorrinolaringol Esp 2011; 62: 71-3.

4. Verge J; Aguilar M; Toledo M. De granuloma maligno de la línea media a linfoma T/NK nasal. Presentación de un caso clínico y actualización del tema. ORL Aragon 2011; 14: $13-7$.

5. Wu X., Li P., Zhao J., Yang X., Wang F., Yang Y.Q., ET AL. A clinical study of 115 patients with extranodal natural killer/T-cell lymphoma, nasal type. Clinical Oncology 2008; 20: 619-25.

6. Tlholoe M; Kotu M; Khammissa R; Vida M; Lemmer J; Feller L. Extranodal Natural Killer/T-cell lymphoma, nasal type: 'midline lethal granuloma'. A case report. Head Face Med 2013; 9: 4.

7. Lim MS, De Leval L, Quintanilla-Martinez L. Commentary on the 2008 WHO classification of mature T-and NK-cell neoplasms. J Hematopathol 2009; 2: 65-73.

8. Gualco G, Domeny-Duarte P, Chioato, et al. Clinicopathologic and molecular features of 122 brazilian cases of nodal and extranodal NK/T- que parece mejorar el control de la recidiva local tras el fracaso del tratamiento convencional con QTP ${ }^{12}$. La mayoría de los pacientes mueren pocos meses después del diagnóstico como consecuencia de las complicaciones del tratamiento con (RTP y QTP), Habitualmente por cuadros sépticos debido a la inmunosupresión ${ }^{14,15}$.

cell lymphoma, nasal type, with EBV subtyping analysis. Am J Surg Pathol 2011; 35: 1195-203.

9. Visnovich A. Linfomas NK. Anatomía patológica. Hematología 2008; 12: 46-7.

10. Fernández M, Peixoto S, Da Silva N, Libório-Kimura T, De Lima L, De Oliveira J. Linfoma extranodal tipo nasal de células T/Natural Killer acometendo mucosa oral de paciente com histórico de leishmaniose. Rev Port Estomatol Med Dent Cir Maxilofac 2015; 56: 251-5.

11. Da Silva V, Batista J, De Castro V, Vasconcelos G, Côrrea T, Alves W. Linfoma Nasosinusal de Células T Natural Killer: Relato de Caso. Arquivos Int Otorrinolaringol 2011; 15: 102-5.

12. Torre A, Llorente S, De Vicente J.C , Junquera J.M, J.S. López-Arranz J.S. Linfoma nasal de células T/NK. Rev Esp Cirug Oral y Maxilofac 2005; 27 : 100-8.

13. Beltramino M, Calmet R, Gatica M. Virus de Epstein-Barr y su relación con el desarrollo de enfermedades linfoproliferativas. Hematologia 2005; 9: 39-54.

14. Proulx GM, Cuadra-Garcia I, Ferry J, Harris NL, Greco WR, KayA U, y cols. Lymphoma of the nasal cavity and paranasal sinuses. Treatment and outcome of early-stage disease. Am J Clin Oncol 2003; 26: 6-11.

15. Prellat J, Sweetenham J, Pickering RM, Brown L, WILKINS B. A single centre study of treatment outcomes and survival in 120 patients with peripheral T-cell non-Hodgkin's lymphoma. Ann Hematol 2002; 81: 267- 72. 